\title{
Evaluation of Supravalvular Changes in Aortic Gradient Following Inverted Y-Patch Repair
}

\author{
Ters Y Şeklinde Yama Tamiri Sonrası Supravalvülar \\ Aort Gradient Değişiminin Değerlendirilmesi
}

\begin{abstract}
Objective: This study presents our single-institute experience regarding the patients who underwent surgical correction via inverted $Y$-patch repair with the diagnosis of supravalvular aortic stenosis. Method: A total of 16 patients who underwent inverted Y-patch (Doty) repair in our center between 2005 and 2019 were retrospectively analyzed. Complications, supravalvular residual gradient measurements, causes of re-operation were evaluated.

Results: Patient population consisted of 9 males, 7 females with an overall mean age of $41.18 \pm 16.14$ months (range: 4 months to 19 years). Eight (50\%) patients were diagnosed with Williams-Beuren syndrome and $3(18.7 \%)$ with bicuspid aortic valve. Three (18.7\%) patients had undergone simultaneous subaortic membrane resection and pulmonary patch plasty was performed in $2(12.5 \%)$ patients. There was one (6.7\%) inhospital death and no mortality was observed during follow-up. The mean follow-up time was $5.25 \pm 3.37$ years. During this period, $2(12.5 \%)$ patients required pulmonary balloon dilatation and one patient repeated Doty repair and aortic valve commissurotomy two years after the initial surgery. Thereafter the same patient needed aortic homograft valve replacement and Doty repair for the third time due to severe aortic insufficiency and suprvalvular aortic stenosis.

Conclusion: Inverted Y-patch repair provides satisfactory results, acceptable reoperation risk, and good overall survival.
\end{abstract}

Keywords: Supravalvular aortic stenosis, doty repair, bicuspid aortic valve

öz

Amaç: Bu çalışma, supravalvüler aort darlığı tanısı ile ters Y-yama onarımı ile cerrahi düzeltme yapılan hastalarla ilgili tek enstitü deneyimimizi sunmaktadır.

Yöntem: 2005-2019 yılları arasında merkezimizde Y-yama (Doty) onarımı yapılan 16 hasta retrospektif olarak incelendi. Komplikasyonlar, supravalvüler rezidüel gradyan ölçümleri, tekrar ameliyat nedenleri değerlendirildi.

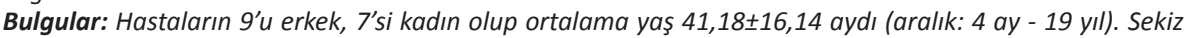
(\%50) hastaya Williams-Beuren sendromu ve $3(\% 18,7)$ hastaya biküspit aort kapağı tanısı konuldu. Ü̧̧ hastaya $(\% 18,7)$ eşzamanlı subaortik membran rezeksiyonu ve 2'sine $(\% 12,5)$ pulmoner yama plasti uygulandı. Bir $(\% 6,7)$ hastane ölümü vardı ve takipte mortalite gözlenmedi. Ortalama takip süresi 5,25 53,37 yıl idi. Takipte, $2(\% 12,5)$ hastada ilk işlemden iki yıl sonra pulmoner arter balon dilatasyonu ve bir hastada tekrarlanan Doty onarımı ve aort kapak komissürotomisi gereksinimi oldu. Daha sonra aynı hastada üçüncü kez aortik aort yetersizliği ve suprvalvüler aort darlığı sebepleriyle aortik homogreft kapak replasmanı ve yeniden Doty onarımı gerekti.

Sonuç: Ters Y-yama onarımı, tatmin edici sonuçlar, kabul edilebilir yeniden operasyon riski ve iyi bir genel sağkalım sağlar.

Anahtar kelimeler: Supravalvüler aort darlığı, doty tamiri, biküspit aort kapağı
Received/Geliş: 31.01 .2020

Accepted/Kabul: 06.02.2020

Published Online/Online Yayın: 31.08.2020

Gökmen Akkaya Ege University School of Medicine, Department of Pediatric Cardiovascular Surgery, Izmir, Turkey - akkayagokmen@gmail.com ORCID: 0000-0002-0509-1971

C. Bilen 0000-0002-9158-5627

O. Tuncer 0000-0001-6495-1639

Y. Atay 0000-0002-5717-0057 Ege University School of Medicine, Department of Pediatric Cardiovascular Surgery, Izmir, Turkey 


\section{INTRODUCTION}

Supravavular aortic stenosis (SVAS) is a rare entity among left ventricle outflow tract obstructions and has an estimated incidence of 1:10.000 live births ${ }^{(1)}$. Although the disease usually manifests itself by narrowing the ascending aorta and sinotubular junction, in diffuse form, involvement of the entire ascending aorta, branches of aortic arch and even descending aorta may coexist with SVAS ${ }^{(2-7)}$. The defective elastin production caused by a microdeletion on chromosome 7 (7q11.23) which leads to reduced elasticity, collagen deposition, increased wall shear stress and thickening of tunica media, is held responsible for the development of SVAS ${ }^{(5-9)}$. The disease may occur sporadically or in a familial form as a component of Williams-Beuren Syndrome (WBS) in conjunction with other various cardiovascular, neurobehavioural, craniofacial and metabolic abnormalities ${ }^{(4,6-9)}$.

The disease often progresses, therefore a surgical correction may be required. The first successful surgical correction was performed by McGoon with a single patch technique in $1956^{(10)}$. Since then, various modifications have been developed. For instance, Doty et al. ${ }^{(11)}$ relieved SVAS with an inverted-Y shaped patch by reconstructing both non-coronary and right coronary sinuses while 3-sinus reconstruction with triple-patch in an attempt to provide symmetrical augmentation was introduced by Brom et al. ${ }^{(12)}$. Recently, the two aforementioned methods are the most accepted techniques worldwide. However, there is no convincing evidence that any of these is superior to another ${ }^{(7,8)}$. On the other hand, there are still several controversies in the patient management for example, optimal timing for surgery has not been established yet ${ }^{(5,8)}$.

Herein, we reviewed our results in the Doty technique performed on patients in order to determine the factors related to adverse effects and late complications and to present our mid- and long-term outcomes.

\section{MATERIAL and METHODS}

This study protocol was approved by the Ethics Committee of Ege University with a decision number
$19-1 T / 34$ and was conducted in accordance with the principles of the Declaration of Helsinki.

The medical records of a total 16 patients who underwent Doty repair with the diagnosis of SVAS in our institute between 2005 and 2019 were retrospectively reviewed. The cases who had acquired secondary SVAS due to the prior cardiac surgeries were excluded from the study. The patient characteristics', associated cardiac defects, intraoperative and postoperative data, morbidity and mortality rates and transthoracic echocardiography (TTE) findings in regular follow-up were evaluated.

All patients were examined via TTE and conventional angiography to confirm the initial diagnosis and to measure the gradient. Moreover, in 8 cases with suspect concomitant cardiac abnormalities computed tomography or magnetic resonance imaging was performed for further assessment.

The patients were discussed in a pediatric heart council profoundly by a heart team comprised of pediatric heart surgeons, cardiologists, intensive care unit specialists and pediatric radiologists. The surgical correction was decided for the patients in the presence of severe $(>50 \mathrm{mmHg})$ or moderate (21-49 $\mathrm{mmHg}$ ) degree of stenosis with accompanying symptoms or significant left ventricularhypertrophy.

\section{Surgical Procedure}

Mediastinal access was achieved through a median sternotomy. Following systemic heparin administration, cannulation of the ascending aorta was performed in the most possible distal location, selective venous cannulation was achieved and venting cannula was inserted into the left superior pulmonary vein, then cardiopulmonary by-pass was established. Afterwards, aortic cross-clamp was applied and diastolic cardiac arrest was initiated by antegrade cardioplegia solution under moderate hypothermia. A longitudinal incision on the anterior surface of the ascending aorta was made which was extended towards the middle of the non-coronary sinus and to the left side of the right coronary sinus (Figure 1). The narrowed segment was enlarged via Dacron patch fashioned as inverted $Y$ (Figure 2). The repair 


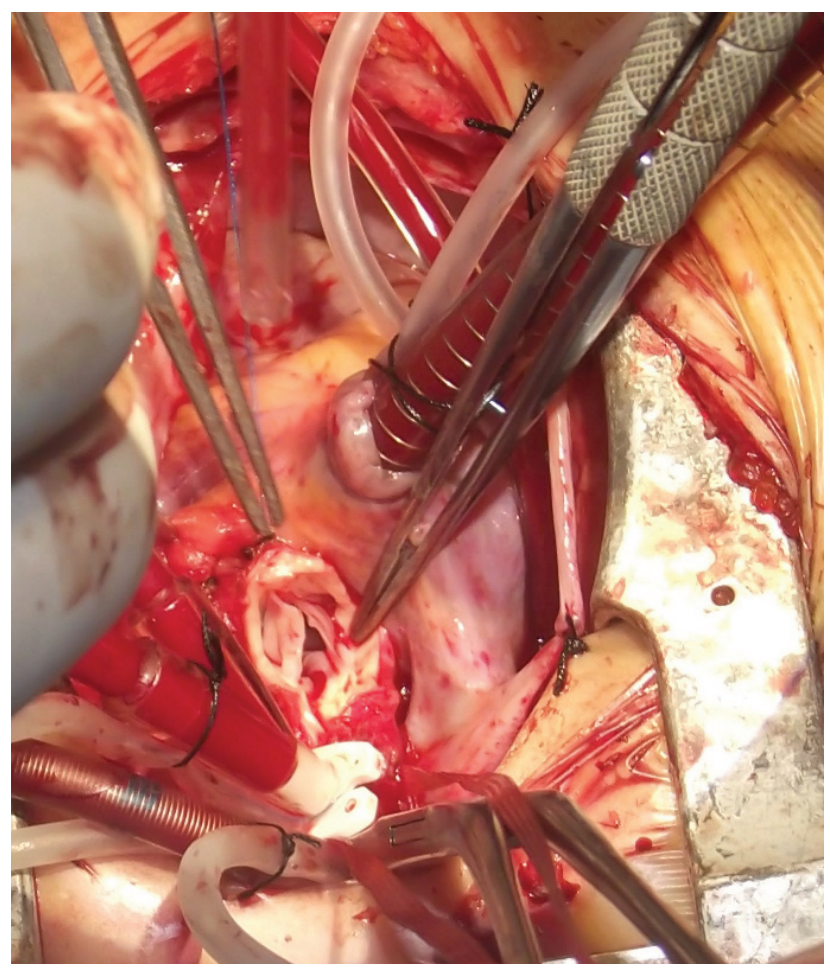

Figure 1. An incision was extended in order to release the obstruction towards the non-coronary and right coronary sinuses.

was completed by running polypropylene sutures.

The postoperative TTE examinations were performed before discharge, at first, third, and sixth months after surgery, then repeated by yearly intervals.

\section{Statistical Analysis}

Statistical analysis was performed using SPSS for Windows, Version 22.0 (SPSS Inc., Chicago, IL, USA). Descriptive statistics were expressed in mean \pm standard deviation (SD), median, number ( $\mathrm{n})$, and frequency (\%). Owing to the limited sample size, comparisons of related samples were performed using a nonparametric test (Wilcoxon test) instead of a parametric test. A p-value of $<0.005$ was considered statistically significant.

\section{RESULTS}

A total of 16 (9 males, 7 females) patients underwent Doty repair with the diagnosis of SVAS in our center between January 2005 and March 2019. The

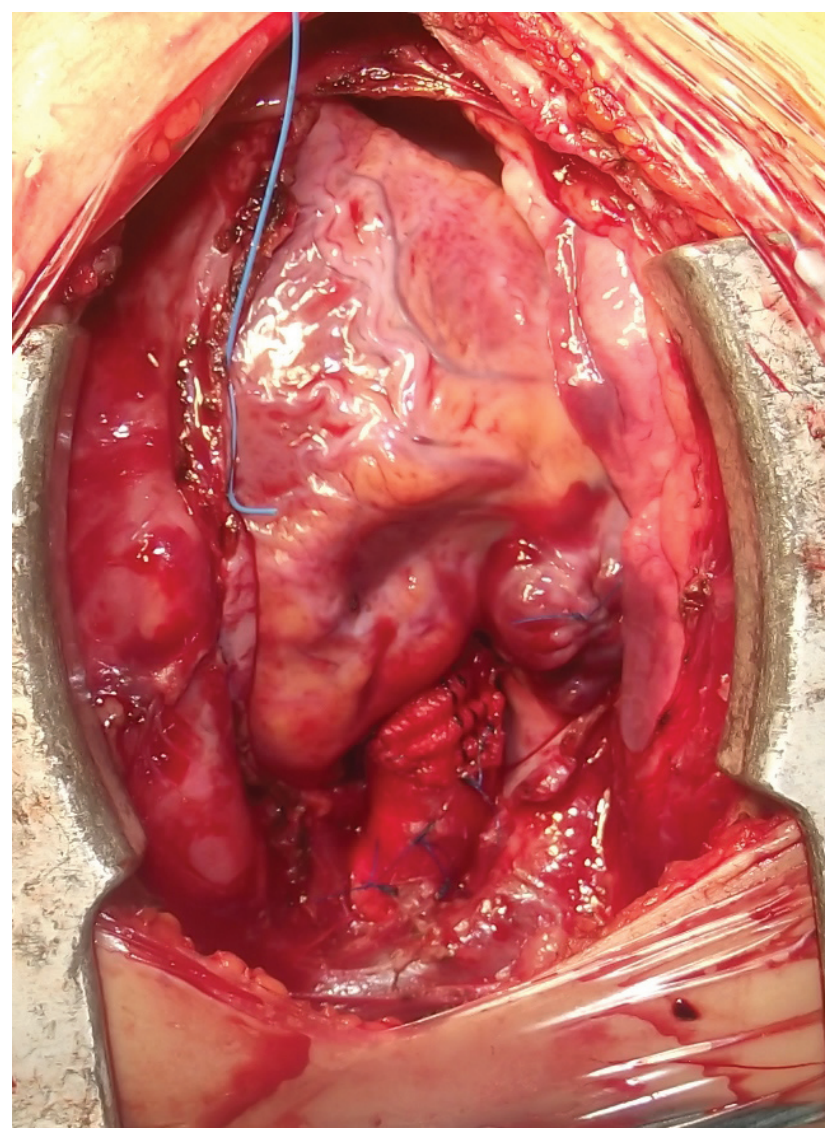

Figure 2. A view of ascending aorta after the enlargement was performed via Dacron patch fashioned as inverted $\mathrm{Y}$.

mean age was 41 months (range: 4 months - 19 years, median 2 years) and six (37\%) of them were $<12$ months of age at the time of the operation. WBS diagnosis was confirmed in $8(50 \%)$ of patients by genetics. Patient characteristics are presented in Table 1.

Overall 12 patients were asymptomatic or mildly symptomatic. Three patients (18\%) had symptoms of congestive heart failure while 4 (25\%) were suffering from dyspnea. Preoperative TTE examinations revealed mean peak supravalvular aortic gradient as $72.87 \pm 11.20 \mathrm{mmHg}$. Moreover, 6 (37\%) patients had moderate and $2(12 \%)$ patients had mild aortic valve regurgitation. Therewithal, 4 (25\%) patients had associated bicuspid aorta, meanwhile, three (18\%) had a subaortic discrete membrane and 2 (12\%) had pulmonary artery stenosis. Due to the concomitant anomalies, 3 subaortic discrete membrane resections and 2 pulmonary arterioplasties were perfor- 
Table 1. Demographics and clinical data of the patients.

\begin{tabular}{lc}
\hline Variable & Value \\
\hline Gender & \\
Male/Female & $9 / 7$ \\
& \\
Age (month) & $41.18 \pm 16.14$ \\
Weight (kg) & $17.43 \pm 12.29$ \\
Williams-Beuren syndrome & $8(50 \%)$ \\
& \\
Supravalvular stenosis type & $14(87.5 \%)$ \\
Discrete & $2(12.5 \%)$ \\
Diffuse & \\
& \\
Additional cardiovascular abnormality & $4(25 \%)$ \\
Bicuspid aortic valve & $2(12.5 \%)$ \\
Peripheral pulmonary stenosis & $3(18 \%)$ \\
Subaortic discrete membrane & \\
\hline
\end{tabular}

Data are presented as mean \pm SD or number.

Table 2. Operative and postoperative details and echocardiographic findings.

\begin{tabular}{|c|c|}
\hline Variable & Valid \\
\hline \multicolumn{2}{|l|}{ Additional surgery } \\
\hline Pulmonary arterioplasty & 2 \\
\hline $\begin{array}{l}\text { Subaortic discrete membrane } \\
\text { resection }\end{array}$ & 3 \\
\hline \multicolumn{2}{|l|}{ Operative findings } \\
\hline Aortic X-Clamp time (min) & $55.81 \pm 18.00$ \\
\hline Total bypass time (min) & $79.43 \pm 20.25$ \\
\hline Intensive care stay (hours) & $28.37 \pm 18.11$ \\
\hline Intubation Time (hours) & $11.43 \pm 22.59$ \\
\hline Hospital stay (days) & $6.56 \pm 1.20$ \\
\hline \multicolumn{2}{|c|}{ Aortic insufficiency (preoperative/postoperative) } \\
\hline Mild & $6 / 2$ \\
\hline Moderate & $3 / 0$ \\
\hline \multicolumn{2}{|c|}{ Aortic stenosis (preoperative/postoperative) } \\
\hline Mild & $2 / 0$ \\
\hline Moderate & $2 / 1$ \\
\hline \multicolumn{2}{|l|}{ Postoperative Interventions } \\
\hline Balloon pulmonary angioplasty & 2 \\
\hline Doty+aortic valve commisurotomy & 1 \\
\hline Aortic homograft replacement & 1 \\
\hline \multicolumn{2}{|l|}{ SVAS peak gradient (mmHg) } \\
\hline Preoperative & $72.87 \pm 11.20$ \\
\hline Postoperative before discharge & $15.75 \pm 3.39$ \\
\hline Last follow-up & $13.25 \pm 2.81$ \\
\hline Duration of follow-up (years) & $5.25 \pm 3.37$ \\
\hline
\end{tabular}

SVAS: Supravalvular aortic stenosis; Data are presented as mean $\pm S D$ or number.

med. The remaining 2 cases had WBS syndrome and although they had no significant narrowing in the main pulmonary artery, the gradient in pulmonary branches was measured as 40 and $55 \mathrm{mmHg}$ respec-
Table 3. Peak pressure gradient changes of supravalvuler aorta.

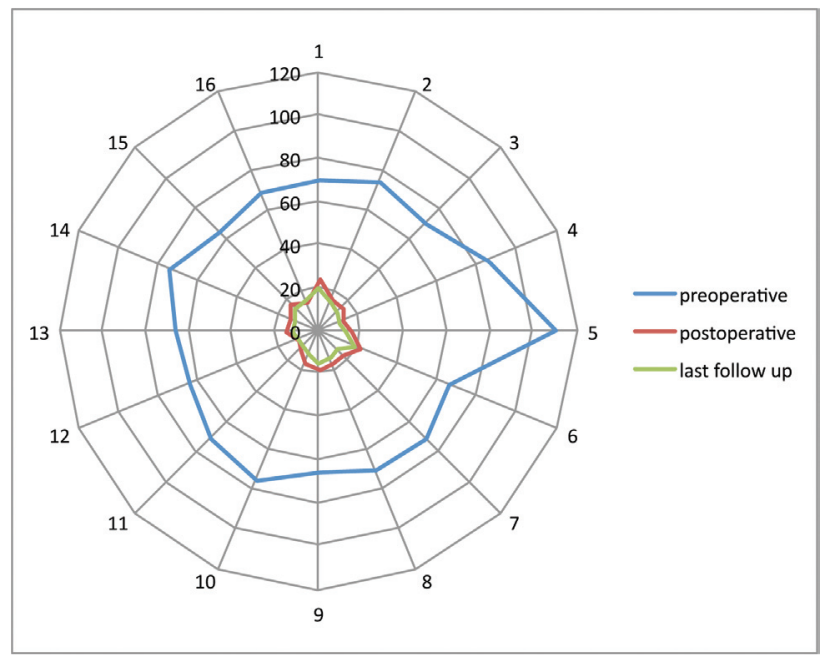

tively, therefore an additional surgical approach is required. Nonetheless, 3 cases with bicuspid aorta had a mild or moderate degree of stenosis, however additional surgical procedure was not required for them. Operative data were shown in Table 2.

Only one $(7 \%)$ inpatient mortality occurred. This patient was 6 months old and weighed $6 \mathrm{~kg}$. In the surgical procedure, additionally dilatation of ascending aorta and hemiarch with the Dacron patch were performed in diffuse form of SVAS. Furthermore, right pulmonary augmentation was performed from bifurcation level towards hilum using a porcine pericardial patch. Although preoperative conventional angiography had not demonstrated any coronary anomalies, during the surgical process, a slight circumferential thickening of the left main ostium and the right coronary artery was observed. Nevertheless, coronary osteoplasty was not required. Then, the patient weaned from cardiopulmonary by-pass with a high inotrope score. Subsequently, ECMO initiated owing to cardiac insufficiency at postoperative tenth hour. Despite all, the patient died as a consequence of low cardiac output on the first postoperative day.

On the other hand, a patient had stayed unusually longer in the intensive care unit ( 3 days) and hospital (14 days) due to pneumonia as an early complication. 
The patients were monitored during follow-up via TTE examinations on the first, third, and sixth months postoperatively. Then, TTE was repeated at yearly intervals. The mean duration of follow-up was $5.25 \pm 3.37$ years. TTE examinations before discharge measured supravalvular aortic gradient as $15.75 \pm 3.39 \mathrm{mmHg}$ and this finding was significant when compared to preoperative values $(p<0.001)$. Although in the majority of patients, the last TTE examinations revealed a decrease in gradient measurements in comparison with postoperative outcomes, the difference was not significant $(p=0.154)$ (Table 3).

During the follow-up, two patients required pulmonary balloon angioplasty due to segmental stenosis 18 and 27 months after the operation. The stenosis relieved with angioplasty and the reduction in gradients were achieved from 45 to 18 and 40 to 15 $\mathrm{mmHg}$, respectively. Postoperatively, two patients had mild aortic regurgitation and one patient had mild aortic stenosis. The case with aortic valve stenosis had bicuspid aorta and peak systolic gradient rapidly began to develop one year after initial Doty repair. In the following year, the last TTE demonstrated $85 \mathrm{mmHg}$ supravalvular and $35 \mathrm{mmHg}$ valvular gradient, therefore reoperation was concluded two years after the first corrective surgery. In the surgical process, Doty repair was repeated and valvular commissurotomy was performed. The perioperative transesophageal echocardiography revealed a remaining $13 \mathrm{mmHg}$ supravalvular gradient without any concurrent valvular gradient. Only, trivial aortic regurgitation was detected. However, after six months, supravalvular gradient had begun to increase in subsequent examinations. The last TTE examination revealed an $80 \mathrm{mmHg}$ gradient with severe aortic regurgitation. Thus, after two years, these findings warranted a surgical repair, therefore $19 \mathrm{~mm}$ sized aortic valve homograft was inserted and Doty repair was repeated for the third time. Later on, the patient was discharged without any residual gradient and TTE examinations in follow-up revealed similar findings.

\section{DISCUSSION}

In this retrospective clinical study, we assessed 14-year outcomes of a single institute in patients who had Doty repair with the diagnosis of SVAS and demonstrated acceptable overall survival and low re-intervention rate.

We tend to utilize inverted bifurcated-patch aortoplasty in the repair of SVAS. Thus, we were able to shorten overall suture line and avoid possible left coronary artery damage. Moreover, we are of the opinion that shortening of cross-clamp and cardiopulmonary bypass time may prevent their detrimental effect on the already hypertrophied left ventricle (5). However, some authors suggest that symmetric three sinus augmentation provides better results, while some others recommend patchless slide aortoplasty due to theoretic advantage of improved preservation of growth potential ${ }^{(5-9)}$. Nevertheless, the question about which intervention is optimal remains unclear.

The main goal of the surgery is to achieve an adequate relief in sinotubuler junction and all methods have proven themselves as reliable with similar outcomes. Previous studies found negligible or no difference among them. For instance, Kramer et al. (13) found $90 \%$ survival at 10 years in Doty repair patients while $91 \%$ at three-patch repair group. Considering all, even Padalino et al. ${ }^{(14)}$ were not able to conclude a certain decision about optimal repair method in their multicentre study using data from the European Congenital Heart Surgeons Association with the largest cohort including 301 patients in the literature so far. They stated that outcomes are related to patients' characteristics rather than surgical choice.

Several risk factors have been defined in prior studies such as diffuse-type SVAS, WBS and infancy $(6,9,14)$. Compatible with this, only one ,npatient mortality occurred in our cohort as a result of low cardiac output on the first postoperative day. This patient was a 6-month-old infant and had a diffuse type of SVAS then required ECMO support postoperatively. Similarly, Donald et al. ${ }^{(15)}$ reported two deaths in their case series among a total of 46 patients and 
one of these was an infant that required additional pulmonary patch plasty and ventricular assist device.

On the other hand, Liu et al. ${ }^{(16)}$ identified male gender, preoperative aortic stenosis, and peak gradient of $\geq 90 \mathrm{mmHg}$ as risk factors for residual aortic stenosis while age $<2$ years, bicuspid aortic valve, and diffuse type aortic stenosis were not.

However the short duration of follow-up, such as in this study (average of 8 years) may be misguiding when considered that reoperations are needed typically after a decade. However, prior studies have determined pulmonary arterial stenosis as a risk factor for mortality in the long term and catheter interventions, and highlighted the importance of close follow-up (13-16). Although some authors observed a decrease of more than $10 \mathrm{mmHg}$ or normalization of the gradient over the stenotic site in the majority of patients, generally balloon angioplasty is commonly utilized in order to achieve an intended relief ${ }^{(15,16)}$.

Only the patient with bicuspid aorta and postoperative residual stenosis had $13 \mathrm{mmHg}$ residual stenosis requiring surgical reoperation. These complications are frequently observed in recent articles. For instance, Roemers et al. ${ }^{(17)}$ suggest a nonsymmetrical correction in the presence of bicuspid aortic valve and prefer to enlarge the sinuses to achieve the best appearance. Nonetheless, Kramer et al. (13) reoperated 6 patients in their cohort and 4 of them reoperated because of recurrent obstruction of the supravalvular aorta at postoperative 5 months and 3.5 years.. Additionally, two cases underwent aortic valve replacement due to severe stenosis. In a study conducted by Padalino et al. ${ }^{(14)}$, the researchers performed 8 redo SVAS and 7 aortic valve replacements. These seven cases were caused by aortic stenosis after a median interval of 5.7 (0.8-22.3) years. In our case, we avoided replacing the valve because of younger age of our patient. Furthermore, sufficient relief was achieved by aortic commissurotomy. However, another surgical approach became necessary due to development of progressive regurgitation and restenosis. Nevertheless, Kari et al. ${ }^{(18)}$ evaluated the progression of aortic regurgitation after different repair techniques for congenital aortic valve stenosis and determined that despite improved early outcomes, aortic regurgitation rmay occur up to $40 \%$ of the cases over a medium-term followup period following the standard procedure of commissurotomy. On the other hand, aortic regurgitation may occur after surgical treatment even in a valve with usual function and morphology. Although the degree of aortic regurgitation improves after surgical correction, aortic valve replacement, for this reason, is not uncommon and has been reported by numerous authors so far ${ }^{(2-9,12-17)}$.

This study had several limitations due to its intrinsic retrospective design and small sample size. Moreover, we were not able to compare different surgical techniques hence we only performed Doty repair. Therefore, acquired data was not sufficient to determine risk factors and to carry out further comparative analysis.

To summarize, Doty repair is an effective and feasible procedure in the surgical correction of SVAS, hence it provides satisfactory results, low surgical risk, and good long-term survival. However, previously identified risk factors may cause late adverse events, thus close follow-up in such patients is essential.

\section{Scientific Responsibility Statement}

The authors declare that they are responsible for the article's scientific content including study design, data collection, analysis and interpretation, writing, some of the main line, or all of the preparation and scientific review of the contents and approval of the final version of the article.

\section{Animal and Human Rights Statement}

All procedures performed in this study were in accordance with the ethical standards of the institutional and/or national research committee and with the 1964 Helsinki Declaration and its later amendments or comparable ethical standards. No animal or human studies were carried out by the authors for this article. 
Ethics Committee Approval: This study protocol was approved by Ege University Ethics Committee with decision no 19-1T / 34.

Conflict of Interest: The authors declared no conflicts of interest with respect to the authorship and/ or publication of this article.

Funding: The authors received no financial support for the research and/or authorship of this article.

Informed Consent: Consent form obtained from parents.

\section{REFERENCES}

1. Kouchoukos NT. "Kirklin/Barratt-Boyes' cardiac surgery: morphology, diagnostic criteria, natural history, techniques, results, and indications". $3^{\text {rd }}$ edition. Philadelphia (PA): Churchill Livingstone; 2003. p. 1265-313.

2. Kaushal S, Backer CL, Patel S, Gossett JG, Mavroudis C. Midterm outcomes in supravalvular aortic stenosis demonstrate the superiority of multisinus aortoplasty. Ann Thorac Surg. 2010;89:1371-7. https://doi.org/10.1016/j.athoracsur.2010.02.019

3. Mitchell MB, Goldberg SP. Supravalvar aortic stenosis in infancy. Semin Thorac Cardiovasc Surg Pediatr Card Surg Annu. 2011;14:85-91. https://doi.org/10.1053/j.pcsu.2011.01.013

4. Stamm C, Friehs I, Ho SY, Moran AM, Jonas RA, del Nido PJ. Congenital supravalvar aortic stenosis: a simple lesion? Eur J Cardiothorac Surg. 2001;19:195-202. https://doi.org/10.1016/\$1010-7940(00)00647-3

5. Mongé MC, Eltayeb OM, Costello JM, Johnson JT, Popescu AR, Rigsby CK, et al. Brom aortoplasty for supravalvular aortic stenosis. World J Pediatr Congenit Heart Surg. 2018;9(2):139-46. https://doi.org/10.1177/2150135118754520

6. Fricke TA, d'Udekem Y, Brizard CP, Wheaton G, Weintraub RG, Konstantinov IE. Surgical repair of supravalvular aortic stenosis in children with Williams syndrome: a 30-year experience. Ann Thorac Surg. 2015;99:1335-41. https://doi.org/10.1016/j.athoracsur.2014.11.044

7. Deo SV, Burkhart HM, Schaff HV, Li Z, Stensrud PE, Olson TM, et al. Late outcomes for surgical repair of supravalvar aortic stenosis. Ann Thorac Surg. 2012;94(3):854-9. https://doi.org/10.1016/j.athoracsur.2012.04.022

8. Scott DJ, Campbell DN, Clarke DR, Goldberg SP, Karlin DR,
Mitchell MB. Twenty-year surgical experience with congenital supravalvar aortic stenosis. Ann Thorac Surg. 2009;87:1501-8. https://doi.org/10.1016/j.athoracsur.2009.01.070

9. Metton O, Ben Ali W, Calvaruso D, Bonnet D, Sidi D, Raisky O, et al. Surgical management of supravalvular aortic stenosis: does Brom three-patch technique provide superior results? Ann Thorac Surg. 2009;88(2):588-93. https://doi.org/10.1016/j.athoracsur.2009.04.107

10. McGoon DC, Mankin HT, Vlad P, Kirklin JW. The surgical treatment of supravalvular aortic stenosis. J Thorac Cardiovasc Surg. 1961;41(1):125-33.

11. Doty DB, Polansky DB, Jenson CB. Supravalvular aortic stenosis. Repair by extended aortoplasty. J Thorac Cardiovasc Surg. 1977;74(3):362-71. https://doi.org/10.1016/S0022-5223(19)41350-0

12. Brom AG. Obstruction of the left ventricular outflow tract. In: Khonsari S, editor. Cardiac Surgery: Safeguards and Pitfalls in Operative Technique, 1st edition. Rockville: Aspen Publishers; 1988. p. 276-80.

13. Kramer P, Absi D, Hetzer R, Photiadis J, Berger F, AlexiMeskishvili V. Outcome of surgical correction of congenital supravalvular aortic stenosis with two- and three-sinus reconstruction techniques. Ann Thorac Surg. 2014;97:63440. https://doi.org/10.1016/j.athoracsur.2013.09.083

14. Padalino MA, Frigo AC, Comisso M, Kostolny M, Omeje I, Schreiber C, et al. Early and late outcomes after surgical repair of congenital supravalvular aortic stenosis: a European Congenital Heart Surgeons Association multicentric study. Eur J Cardiothorac Surg. 2017;52(4):789-97. https://doi.org/10.1093/ejcts/ezx245

15. Donald JS, Fricke TA, Griffiths S, Konstantinov IE. Surgical correction of congenital supravalvular aortic stenosis. Oper Tech Thorac Cardiovasc Surg. 2016;21:202-10. https://doi.org/10.1053/j.optechstcvs.2017.05.003

16. Liu H, Gao B, Sun Q, Du X, Pan Y, Zhu Z, et al. Surgical strategies and outcomes of congenital supravalvular aortic stenosis. J Card Surg. 2017;32:652-8. https://doi.org/10.1111/jocs.13213

17. Roemers R, Kluin J, de Heer F, Arrigoni S, Bökenkamp R, van Melle J, et al. Surgical correction of supravalvar aortic stenosis: 52 years' experience. World J Pediatr Congenit Heart Surg. 2018;9(2):131-8. https://doi.org/10.1177/2150135117745004

18. Kari FA, Kroll J, Kiss J, Hess C, Stiller B, Siepe M, et al. Progression of aortic regurgitation after different repair techniques for congenital aortic valve stenosis. Pediatr Cardiol. 2016;37:84-9. https://doi.org/10.1007/s00246-015-1243-0 